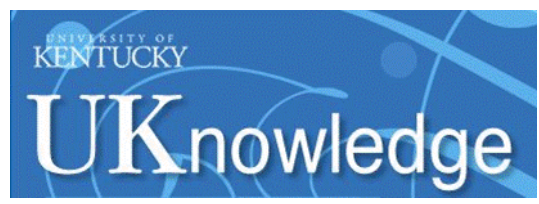

University of Kentucky

UKnowledge

Biosystems and Agricultural Engineering Faculty Publications

$11-2002$

\title{
Mechanical Properties of Corn and Soybean Meal
}

\author{
Marek Molenda \\ Polish Academy of Sciences, Poland \\ Michael D. Montross \\ University of Kentucky, michael.montross@uky.edu \\ Jozef Horabik \\ Polish Academy of Sciences, Poland \\ Ira Joseph Ross \\ University of Kentucky
}

Follow this and additional works at: https://uknowledge.uky.edu/bae_facpub

Part of the Agriculture Commons, and the Bioresource and Agricultural Engineering Commons

Right click to open a feedback form in a new tab to let us know how this document benefits you.

\section{Repository Citation}

Molenda, Marek; Montross, Michael D.; Horabik, Jozef; and Ross, Ira Joseph, "Mechanical Properties of Corn and Soybean Meal" (2002). Biosystems and Agricultural Engineering Faculty Publications. 96.

https://uknowledge.uky.edu/bae_facpub/96

This Article is brought to you for free and open access by the Biosystems and Agricultural Engineering at UKnowledge. It has been accepted for inclusion in Biosystems and Agricultural Engineering Faculty Publications by an authorized administrator of UKnowledge. For more information, please contact UKnowledge@lsv.uky.edu. 


\section{Mechanical Properties of Corn and Soybean Meal}

\section{Digital Object Identifier (DOI)}

https://doi.org/10.13031/2013.11408

\section{Notes/Citation Information}

Published in Transactions of the ASAE, v. 45, issue 6, p. 1929-1936.

(c) 2002 American Society of Agricultural Engineers

The copyright holder has granted the permission for posting the article here. 


\title{
Mechanical Properties of Corn And Soybean Meal
}

\author{
M. Molenda, M. D. Montross, J. Horabik, I. J. Ross
}

\begin{abstract}
Ground corn and soybean meal are common ingredients in feed mixes. The knowledge of their mechanical properties is important to the feed manufacturer and consumer. Changes in these properties can lead to abnormally high or low levels of active ingredients in finished feed, thus decreasing its quality. Mechanical properties of wheat, corn meal, and soybean meal were investigated using a modified direct shear apparatus. The moisture content (wet basis), uncompacted bulk density, and particle density were: $10.4 \%, 733 \mathrm{~kg} / \mathrm{m}^{3}$, and $1410 \mathrm{~kg} / \mathrm{m}^{3}$ for soft red winter wheat; $11.4 \%, 583 \mathrm{~kg} / \mathrm{m}^{3}$, and $1350 \mathrm{~kg} / \mathrm{m}^{3}$ for soybean meal; and $11.7 \%, 595 \mathrm{~kg} / \mathrm{m}^{3}$, and $1410 \mathrm{~kg} / \mathrm{m}^{3}$ for corn meal, respectively. A relatively long sliding path of $60 \mathrm{~mm}$ was utilized in shear testing to account for the high compressibility of the materials and minimize boundary effects. The compressibility of the materials was determined at a maximum vertical pressure of $34.4 \mathrm{kPa}$, which caused a density increase of $21 \%$ for corn meal while the density of wheat and soybean meal increased by approximately $5 \%$. Frictional properties were tested for seven levels of vertical consolidation pressures ranging from 4.1 to $20.7 \mathrm{kPa}$. The high compressibility of corn meal resulted in severe stick-slip behavior of the frictional force-displacement relationships. The angles of internal friction of wheat, soybean meal, and corn meal were found to be $26.3^{\circ} \pm 0.3^{\circ}, 33.9^{\circ} \pm 0.9^{\circ}$, and $30.7^{\circ} \pm 1.4^{\circ}$, respectively. Cohesion of soybean meal and corn meal was approximately $0.7 \mathrm{kPa}$ without a clear relation to consolidation stress and approximately $0.3 \mathrm{kPa}$ for wheat. With cohesion values lower than $4 \mathrm{kPa}$, all three materials should be treated as free-flowing in terms of Eurocode 1. Corn and soybean meals are known to cause flow problems in practice that were not confirmed during testing. In practical storage conditions, materials undergo a longer consolidation period. Our tests have shown that with processes that have a short duration and low consolidation pressures, these materials should be treated as free-flowing.
\end{abstract}

Keywords. Granular feeds, Direct shear test, Internal friction angle, Unconfined yield strength, Stick-slip.

A utomation and increased scale of operation in the feed industry in recent decades has led to an increase in the amount of raw materials, ingredients, and finished feeds used in granular form (bulk solids). At the same time, handling bulk solid materials is one of the least understood areas associated with solid processing plants (Knowlton et al., 1994). For that reason, mechanics of granular materials has gained growing interest among researchers and industrial practitioners. New theoretical approaches and experimental methods have been developed for procedures such as material characterization and bin design. Bin design based on Janssen's equation with the necessary material parameters (bulk density, coefficient of friction on the wall, and pressure ratio) allows for calculation of wall and floor loads with acceptable accuracy. Although 100 years old, Janssen's equation is still the most widely used analytical solution for the calculation of pressures in silos (Wilms, 1991).

Article was submitted for review in April 2002; approved for publication by Food \& Process Engineering Institute Division of ASAE in October 2002.

The authors are Marek Molenda, ASAE Member, Assistant Professor, and Jozef Horabik, ASAE Member, Assistant Professor, Institute of Agrophysics, Polish Academy of Sciences, Lublin, Poland; and Michael David Montross, ASAE Member Engineer, Assistant Professor, and I. Joseph Ross, ASAE Fellow Engineer, Professor Emeritus, Biosystems and Agricultural Engineering Department, University of Kentucky, Lexington, Kentucky. Corresponding author: Michael Montross, 128 Barnhart, University of Kentucky, Lexington, KY 40546-0276, phone: 859-257-3000; fax: 859-257-5671; e-mail: montross@bae.uky.edu.
Bin design as related to flow behavior has been based largely on past experience and trial and error (Cook, 1976). A great deal of work has been done to develop a usable theory of gravity flow for granular materials. The most widely accepted approach was developed by Jenike (1961). The author further refined the approach, but his original testing method and interpretation is still the basis for many codes of practice and later investigations by other researchers. Jenike's testing method originally was used for the estimation of bin design parameters, but the determination of flowability is currently more important. Industrial practitioners report that $95 \%$ of their testing needs are for quality control or product development and not for bin design (Bell et al., 1994). They state that the Jenike shear testing method is relatively complex and time consuming, so there is a need for simpler methods for quality control and material characterization in the industry. Another limitation of the Jenike tester is the short shear path, which makes it difficult to use for very elastic bulk solids.

Flowability is a measure of the quality of granular product that influences its end-use value, for some materials used in the chemical, mineral, pharmaceutical, and food industries (Bell et al., 1994). Flowability of feed ingredients is important during the production of high-quality feeds to ensure that they have consistent composition. Certain nutrients need to be guaranteed at minimum levels and other ingredients below maximum levels that may be toxic at high concentrations. Variation of nutrients in feed effects animal growth and profitability. Variation in flowability of ingredients is a significant source of errors during the weighing and proportioning, resulting in non-uniformity in the finished

Transactions of the ASAE 
feed product. Physical properties of premix carriers should be standardized because their changes can produce abnormally high or low levels of active ingredients in the finished feed (Benson, 1976). Knowlton et al. (1994) stated that three key parameters are required to assess flowability: cohesive strength, wall friction, and compressibility.

Standardized procedures pertain to material characterization under high levels of stress, such as $100 \mathrm{kPa}$ of vertical stress as recommended by Eurocode 1 (1995). The majority of feed operations are performed with shallow layers of granular materials in which vertical stresses are relatively small, but granular materials solidified through consolidation may become useless. Thus, knowledge about material behavior under low vertical stress is valuable for the appropriate design and operation of granular material storage structures. However, determination of material characteristics under low vertical pressures poses particular difficulties. Non-uniform packing of the material as well as non-homogenous shear deformation result in a wide range of material parameters determined by different tests. One possible tool for the determination of properties of elastic materials of biological origin may be the modified direct shear device that was used by Molenda et al. (2000) to determine the coefficient of friction of wheat on corrugated steel. This device allowed for a longer shear path as well as lower vertical pressure relative to the standard Jenike shear tester. The modified direct shear device more accurately reflects the conditions in a shallow layer of highly deformable materials of biological origin.

The objectives of the research reported in this article were to: (1) examine the applicability of the modified direct shear device for investigation of internal friction of biological granular materials under low vertical pressures (below $21 \mathrm{kPa}$ ), and (2) determine the basic mechanical characteristics of two popular feed premix carriers (corn and soybean meal) compared to a free-flowing material (soft red winter wheat).

\section{Materials AND Methods}

Corn meal and soybean meal were chosen for testing from the list of grain products considered as suitable carriers for feed premixes (Benson, 1976). The wheat, corn meal, and soybean meal samples were obtained from a local feed mill. Soft red winter wheat was used as the typical free-flowing material for comparison. Uncompacted bulk densities were determined using the weight per Winchester bushel (USDA, 1999), and the moisture content was determined using the oven method (ASAE Standards, 1997b). The uncompacted bulk densities and moisture contents (wet basis) were: $733 \mathrm{~kg} / \mathrm{m}^{3}$ and $10.4 \%$ for wheat, $566 \mathrm{~kg} / \mathrm{m}^{3}$ and $11.7 \%$ for corn meal, and $583 \mathrm{~kg} / \mathrm{m}^{3}$ and $11.4 \%$ for soybean meal, respectively. The particle densities were determined using an air comparison multipycnometer (Quantachrome MVP-2, Boynton Beach, Fla.). The particle densities for wheat, soybean meal, and corn meal were determined to be 1410 , 1350 , and $1410 \mathrm{~kg} / \mathrm{m}^{3}$, respectively.

\section{Particle Size Distribution}

Particle size distribution of ground materials was determined with standard Tyler Ro-Tap sieve shakers according to ASAE S319.3 (ASAE Standards, 1997a). A set of seven sieves with aperture sizes of 2000, 850, 425, 250, 149, 106, and $75 \mu \mathrm{m}$ with a sample of $400 \mathrm{~g}$ was used with a sieving time of $15 \mathrm{~min}$.

\section{CoMPressibILITY}

Compressibility of the tested materials was determined with an apparatus used by Thompson and Ross (1983) for wheat. The apparatus consisted of a square container with an internal dimension of $30.5 \mathrm{~cm}$ per side and a wall height of $10.2 \mathrm{~cm}$. The material was filled to the top of the container and leveled. The container was then closed with a steel top plate, and a flexible diaphragm mounted on the bottom of the container exerted a known pressure on the grain mass, causing the granular material to compact. The changes in height of the material were measured by a dial gauge that deflected as the material compressed. The internal stress was simulated by applying air pressure under the rubber diaphragm, which was monitored by a manometer. Fourteen levels of vertical pressure in a range from 0 to $34.4 \mathrm{kPa}$ were applied with a holding time of $2 \mathrm{~min}$ after each pressure increment to allow stabilization of material height. Preliminary tests indicated that after 2 min the loading deformationtime curve completed its highly non-linear phase of increase, and this time period was adopted for all compressibility tests. Three replications were conducted for each material.

\section{Internal Friction Parameters $\left(c, \varphi_{c}\right.$, AND $\varphi$ )}

Parameters of internal friction (also termed strength parameters) - cohesion $(c)$, angle of internal friction $\left(\varphi_{c}\right)$, and effective angle of internal friction $(\varphi)$ - were determined with the direct shear device used by Molenda et al. (2000). In this apparatus, a sliding tray with vertical blades is pulled horizontally to create a shear zone as it is moved within the stagnant granular material (fig. 1). The sliding tray with vertical blades $1.6 \mathrm{~mm}$ thick, $13 \mathrm{~mm}$ high, and spaced $51 \mathrm{~mm}$ apart was supported on six pairs of roller bearings that allowed it to move freely in the longitudinal direction of the apparatus. A flexible diaphragm mounted on the bottom of the cover of the apparatus was used to exert a known normal pressure on the material mass in the grain compartment.

Samples of material, $88 \mathrm{~mm}$ deep, were located within the compartment, which was bounded on top by the rubber diaphragm and on the bottom by the UHDP plates and the bottom of the sliding tray. The tray was $0.25 \mathrm{~m}$ wide with $0.61 \mathrm{~m}$ of its length exposed to grain pressure. It was attached through a chain and gear system to a universal test machine (Instron, Canton, Mass.), which allowed for measurement of the force of internal friction in the granular material. The preliminary tests indicated that less than $0.1 \%$ of the force could be attributed to friction in the mechanical assembly of the apparatus; therefore, these effects were neglected during data analysis. A detailed description of the modified direct shear tester can be found in Molenda et al. (2000). Direct shear tests were performed with the original procedure from Jenike (1961), which was adapted for the modified direct shear device. The procedure was:

1. A prescribed mass of material was placed in the compartment of the apparatus.

2. A vertical consolidation reference pressure $\left(\sigma_{r}\right)$ was applied for $5 \mathrm{~min}$ before shearing.

3. The sample was sheared until an asymptotic value of frictional force (steady flow) was approached, and thus 


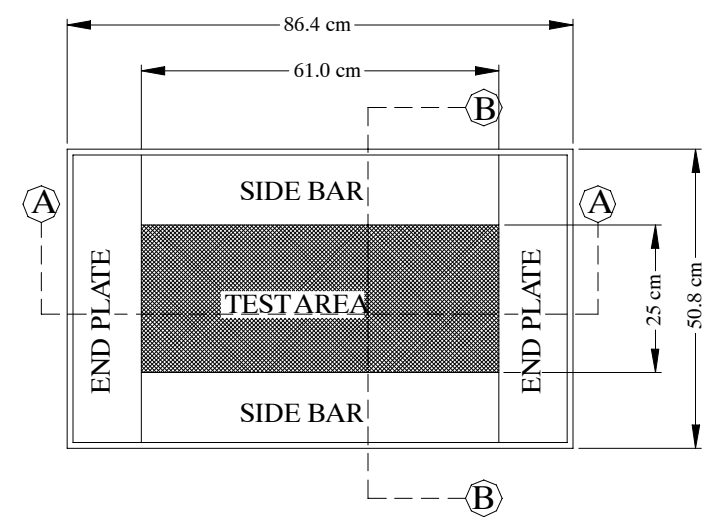

PLAN VIEW

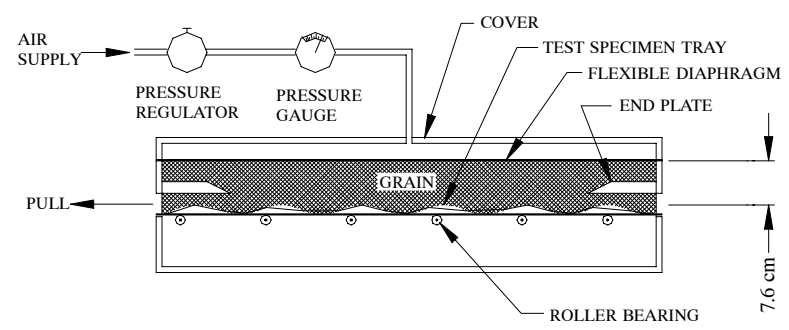

SECTIONA-A

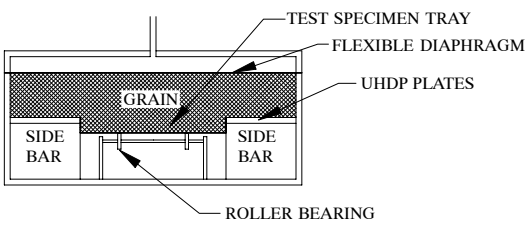

SECTION B-B

Figure 1. Schematic drawing of modified direct shear apparatus for measuring the internal force of friction for granular materials.

values of $\sigma_{\mathrm{r}}$ and $\tau_{\mathrm{r}}$ stresses at the terminus of yield locus were determined.

4. Steps 1 and 2 were repeated to prepare each sample.

5. The sample was sheared until $95 \%$ of an asymptotic value of frictional force (equivalent to $\tau_{r}$, see fig. 5) was measured.
6. The vertical consolidation reference pressure $\left(\sigma_{r}\right)$ was released to zero.

7. Vertical pressure $\left(\sigma_{z 1}\right)$ was applied for 2 min of static holding.

8. The sample was sheared under pressure $\left(\sigma_{z 1}\right)$ until the end of the $60 \mathrm{~mm}$ shear path.

9. Steps 4 through 8 were repeated for vertical pressures of $\sigma_{z 2}$ and $\sigma_{z 3}$, and thus three points on the yield locus were obtained.

Seven levels of vertical reference pressures $\left(\sigma_{\mathrm{r}}\right)$ were used: $4.1,6.2,8.3,10.3,13.8,17.2$, and $20.7 \mathrm{kPa}$. For each level of vertical reference pressure $\left(\sigma_{\mathrm{r}}\right)$, one shear test with this pressure and three tests with lower vertical pressures $\left(\sigma_{\mathrm{z} 1}=0.3 \sigma_{\mathrm{r}}, \sigma_{\mathrm{z} 2}=0.6 \sigma_{\mathrm{r}}\right.$, and $\left.\sigma_{\mathrm{z} 3}=0.9 \sigma_{\mathrm{r}}\right)$ were performed. This allowed for estimation of seven yield loci for each material. The maximum applied consolidation pressure of $20.7 \mathrm{kPa}$ was equivalent to the vertical pressure exerted by a $3 \mathrm{~m}$ deep bed of dry wheat on a bin floor. A shearing speed of $50 \mathrm{~mm} / \mathrm{min}$ was used in all experiments. The shear force was recorded in $0.25 \mathrm{~s}$ time intervals with an accuracy of $\pm 5 \mathrm{~N}$ $(<0.02 \%$ at full scale $)$.

\section{Elastic Parameters ( $E$ AND v)}

An approach proposed by Sawicki (1994) was adopted to estimate Young's modulus and Poisson's ratio. Tests were performed on a $0.17 \mathrm{~m}$ high and $0.21 \mathrm{~m}$ diameter uniaxial compression apparatus, shown schematically in figure 2 . The top cover and base plate of the apparatus had load cells to measure vertical forces. The cylindrical wall of the apparatus was constructed in two semicircular halves cut along the axis. The two halves were connected with four load cells installed in pairs on the two connection lines, which created the cylindrical shape of the wall. This configuration allowed for the determination of vertical pressures exerted on the cover $\left(\sigma_{\mathrm{z} 0}\right)$ and on the bottom $\left(\sigma_{\mathrm{z}}\right)$, as well as the horizontal pressure $\left(\sigma_{\mathrm{x}}\right)$ exerted on the wall. The test chamber of the apparatus was centrally filled through a funnel, and the surface was leveled. A plate was installed, and the material was compressed with a constant velocity of $0.36 \mathrm{~mm} / \mathrm{min}$ until the vertical stress $\left(\sigma_{\mathrm{z} 0}\right)$ reached a value of $100 \mathrm{kPa}$. At this point, the plate was stopped and reversed, resulting in reduction of the vertical force.

A typical response graph of vertical force $(F)$ versus vertical strain $(\varepsilon)$ during loading and unloading is presented
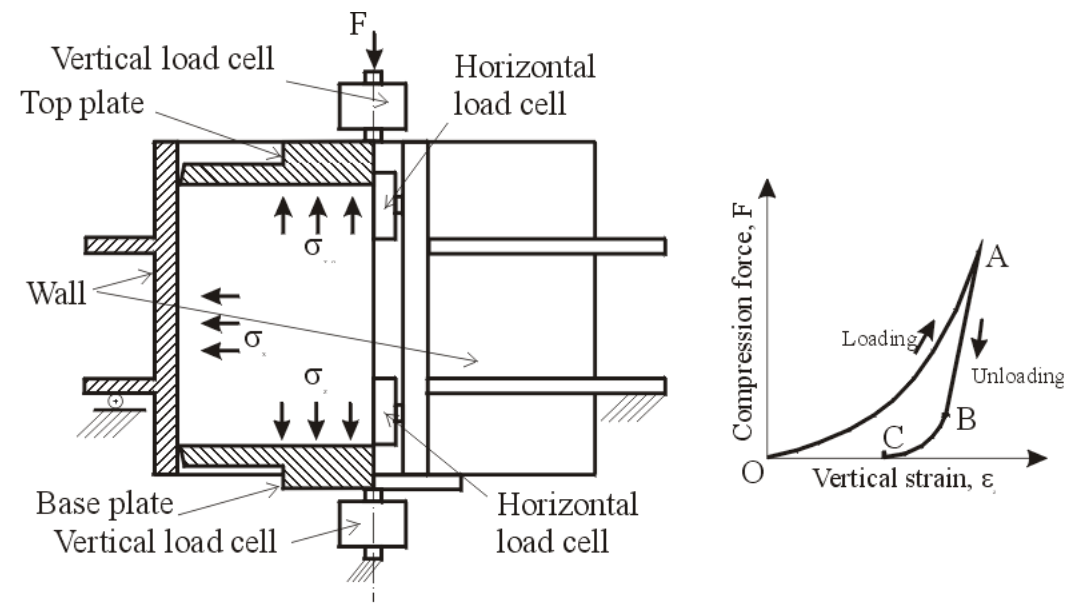

Figure 2. Uniaxial compression apparatus with additional measurement of horizontal pressure. 
in figure 2. Three distinct phases can be distinguished during a single cycle (Sawicki, 1994). During the initial loading (OA), both reversible and irreversible (compaction) strains develop in the material. The first stage of unloading (AB) is characterized by a purely reversible response. The second stage of unloading (BC) is characterized by an increase in volume in which both elastic and plastic strains occur. The loading phase (OA) and second stage of the unloading (BC) of the cycle will not be analyzed in this article. A material behaves as linear elastic during the first stage of unloading. This allows for the determination of the elastic constants, i.e., Young's modulus $(E)$ and Poisson's ratio (v). The reversible response of the material is governed by Hooke's law:

$$
\begin{gathered}
\varepsilon_{x}^{e}=\frac{1}{E}\left[(1-v) \sigma_{x}-v \sigma_{z}\right] \\
\varepsilon_{z}^{e}=\frac{1}{E}\left[\sigma_{z}-2 v \sigma_{x}\right]
\end{gathered}
$$

where $\varepsilon_{\mathrm{x}}$ and $\varepsilon_{\mathrm{z}}$ are horizontal and vertical strains, respectively. The superscript $e$ denotes the elastic part of the strain. According to the assumption $\left(\varepsilon_{x}{ }^{A}-\varepsilon_{x}{ }^{B}\right)=0$, and from equation 1 , it follows that:

$$
\frac{1-v}{v}=\frac{\sigma_{z}^{A}-\sigma_{z}^{B}}{\sigma_{x}^{A}-\sigma_{x}^{B}}=a
$$

where $a$ denotes slope of the linear part of the unloading path in the $\sigma_{\mathrm{x}}$ and $\sigma_{\mathrm{z}}$ system of coordinates. Equation 3 allows for the determination of Poisson's ratio. With no change in plastic strain, $\varepsilon_{\mathrm{z}}^{\mathrm{p}, \mathrm{A}}$ equals $\varepsilon_{\mathrm{z}}^{\mathrm{p}, \mathrm{B}}$, which equals a constant, and Young's modulus follows from equations 2 and 3 as:

$$
E=\frac{\sigma_{z}^{A}-\sigma_{z}^{B}}{\varepsilon_{z}^{A}-\varepsilon_{z}^{B}}\left[1-\frac{2}{a(1+a)}\right]=E^{*}\left[1-\frac{2}{a(1+a)}\right]
$$

where $E^{*}$ denotes slope of the linear part of unloading path in the $\sigma_{\mathrm{x}}$ and $\varepsilon_{\mathrm{Z}}$ space.

\section{Results AND Discussion \\ Particle Size Distribution}

Particle size distribution by mass on each sieve is shown in figure 3 . Soybean meal had $52 \%$ of the particles retained on the $841 \mu \mathrm{m}$ aperture sieve, and $85 \%$ of the particles were larger than $420 \mu \mathrm{m}$. Soybean meal was more uniform than corn meal. Only $31 \%$ of corn meal was retained on the 2000 and $841 \mu \mathrm{m}$ sieves. In practice, particles with sizes below $400 \mu \mathrm{m}$ are considered fine and highly compressible (Johanson, 2000). The particle size distribution of corn meal indicates it will have a high compressibility as compared to soybean meal. An increase in the amount of fine particles is usually associated with decreased flowability. The two materials were standard products of the same feed mill, so the observed distribution may be considered typical. However, according to Johanson (2000), even among relatively standard materials such as flour, products from different manufacturers vary in particle size distribution and essential flow properties, which is likely also true for the products used in these tests.

\section{Density-Pressure Relationships}

Changes in bulk density of the materials as a function of consolidation pressure are shown in figure 4 for three replications of each measurement. Under compaction, the bulk density of wheat and soybean meal increased by approximately $5 \%$ (from $736 \mathrm{~kg} / \mathrm{m}^{3}$ to $770 \mathrm{~kg} / \mathrm{m}^{3}$ and from $585 \mathrm{~kg} / \mathrm{m}^{3}$ to $617 \mathrm{~kg} / \mathrm{m}^{3}$, respectively), while the bulk density of corn meal increased by $21 \%$ (from $639 \mathrm{~kg} / \mathrm{m}^{3}$ to $773 \mathrm{~kg} / \mathrm{m}^{3}$ ). Following Clower et al. (1973), an equation of the form:

$$
\rho=\rho_{o}+A \sigma^{0.5}
$$

was fitted to the data using a non-linear regression procedure. The fitted equations are presented in table 1. High coefficients of correlation (R) indicated a good approximation of the experimental data using a parabolic equation. Parameter $A$ had nearly a five-fold difference between soybean meal $(A=5.81)$ and corn meal $(A=27.04)$, which clearly indicates the large difference in compressibility of the two materials.

\section{Frictional Characteristics}

A typical set of data collected for soybean meal is shown in figure 5 . Shear tests shown were performed on soybean meal with a reference pressure $\left(\sigma_{\mathrm{r}}\right)$ of $20.7 \mathrm{kPa}$ and three levels of vertical pressure $\left(\sigma_{z}\right): 6.2,12.4$, and $18.6 \mathrm{kPa}$. The

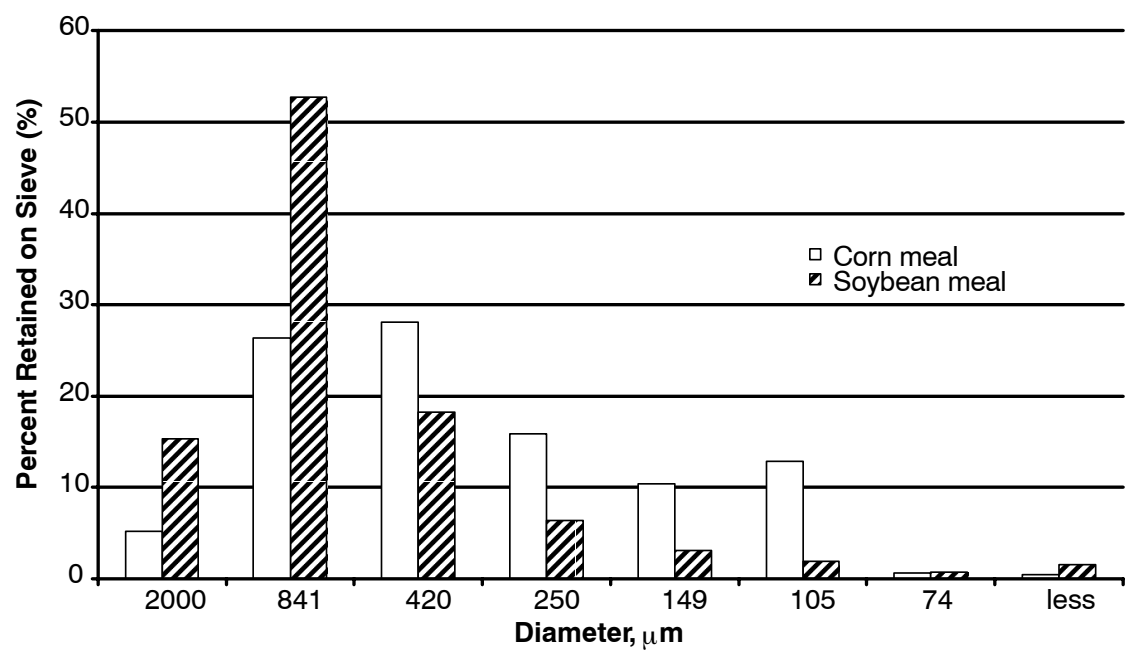

Figure 3. Particle size distribution by mass for soybean meal and corn meal on each sieve. 


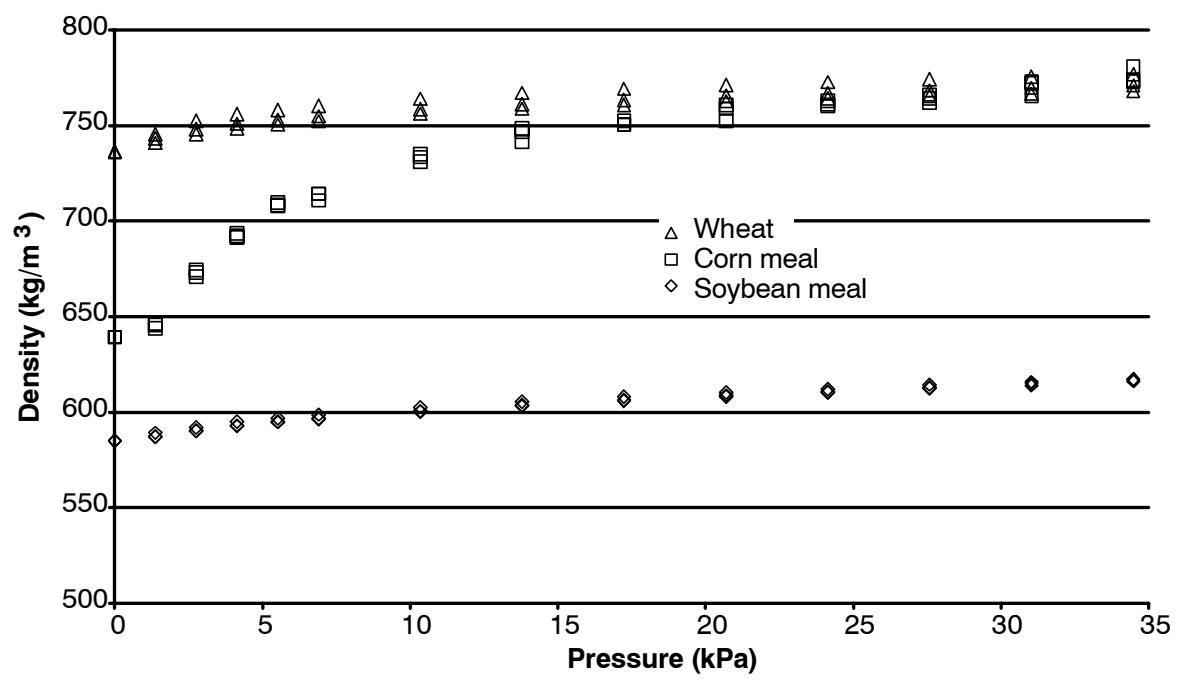

Figure 4. Relationships between the bulk density and vertical pressure determined for wheat, soybean meal, and corn meal.

Table 1. Relationship between bulk density $\left(\rho, \mathbf{k g} / \mathrm{m}^{3}\right)$ and vertical pressure $(\sigma, \mathrm{kPa})$ for tested materials.

\begin{tabular}{llc}
\hline Materials & \multicolumn{1}{c}{ Equation } & $\mathrm{R}$ \\
\hline Wheat & $\rho=738.6+6.05(\sigma)^{0.5}$ & 0.9474 \\
Soybean meal & $\rho=582.4+5.81(\sigma)^{0.5}$ & 0.9924 \\
Corn meal & $\rho=631.1+27.04(\sigma)^{0.5}$ & 0.9699 \\
\hline
\end{tabular}

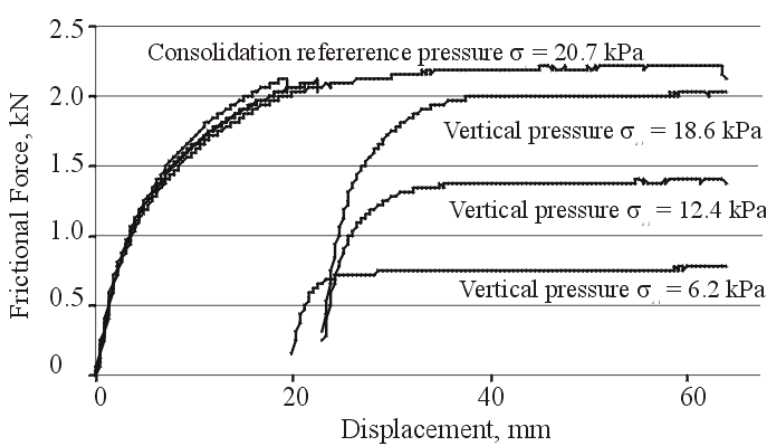

Figure 5. Friction force versus displacement for soybean meal for estimating yield locus at four levels of normal pressure.

magnitude of frictional force under $20.7 \mathrm{kPa}$ of vertical pressure stabilized after approximately $35 \mathrm{~mm}$ of displacement. Preconsolidation under shear stress was completed before the material reached the critical state of continuous flow without a change in stress state, as represented in figure 5 by the three curves approaching a value of $2.08 \mathrm{kN}$, or $95 \%$ of the critical state value.

After the pressure $\left(\sigma_{\mathrm{r}}\right)$ was released, a pressure value of $\sigma_{z}$ was applied and shearing resumed, as represented in figure 5 by the three curves stabilizing at $2.0,1.37$, and $0.74 \mathrm{kPa}$. Pressures were calculated as ratios of forces to surfaces of shear area. Internal friction parameters were calculated using figure 6. A straight line was drawn through the origin of coordinates $(0,0)$ and terminus of the yield locus $\left(\sigma_{\mathrm{r}}, \tau_{\mathrm{r}}\right)$, and an effective angle of internal friction was calculated from:

$$
\varphi=\arctan \left(\frac{\tau_{r}}{\sigma_{r}}\right)
$$

Linear regression was applied to three points $\left(\sigma_{z i}, \tau_{z i}\right)$, and parameters $c$ and $\varphi_{c}$ were estimated in the regression model:

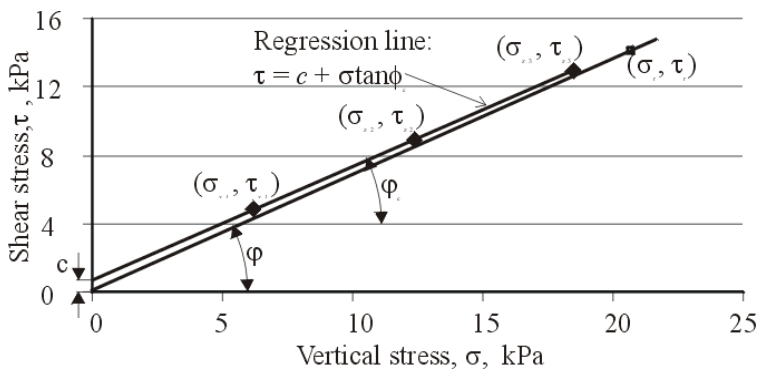

Figure 6. Angles of internal friction ( $\varphi$ and $\left.\varphi_{c}\right)$ and the cohesion $(c)$ for soybean meal at a consolidation reference pressure of $20.7 \mathrm{kPa}$.

$$
\tau=c+\sigma \tan \varphi_{\mathrm{c}}
$$

Coefficients of correlation and parameters with standard deviations are shown in table 2. Numerous materials have curvilinear yield locus, but the high coefficients of correlation (see table 2) point to the linearity of yield locus in corn meal, soybean meal, and wheat. The materials obeyed Coulomb's yield condition. No clear relation was determined between frictional parameters and consolidation pressure. Cohesion will result in a decrease in the coefficient of friction $(\mu)$ with increasing normal load. For dry wheat, a linear relationship between shear stress $(\tau)$ and vertical stress $(\sigma)$ in a range of pressures from 1.4 to $20.7 \mathrm{kPa}$ was found to be:

$$
\tau=0.142+0.487 \sigma(\mathrm{R}=0.999)
$$

Relatively low values of cohesion indicated that dry wheat was a free-flowing material. Non-zero values of cohesion caused a non-linear relationship between the coefficient of friction and normal load.

The equation expressing the coefficient of friction took the form:

$$
\mu=0.487+0.142 / \sigma
$$

Therefore, cohesion adds 0.1 to $\mu$ for a normal load of $1.42 \mathrm{kPa}$, and 0.01 for a normal load of $14.2 \mathrm{kPa}$.

The effective angle of internal friction $(\varphi)$ of wheat was found to be $26.4^{\circ} \pm 0.6^{\circ}$, while values of $\varphi$ for soybean and corn meal were distinctly higher and approximately equal to $36.2^{\circ} \pm 0.6^{\circ}$ and $35.7^{\circ} \pm 0.5^{\circ}$, respectively. Cohesion of wheat was found to be $0.33 \pm 0.07 \mathrm{kPa}$, while for soybean and 
Table 2. Estimated friction parameters for effective angle of internal friction $(\varphi)$, angle of internal friction in the test specimen $\left(\varphi_{c}\right)$, and cohesion $(c)$ for wheat, soybean meal, and corn meal. Correlation coefficient (R) of equation 7 fitted to experimental data with mean and standard deviations.

\begin{tabular}{|c|c|c|c|c|}
\hline $\begin{array}{l}\text { Reference } \\
\text { Pressure } \\
(\mathrm{kPa})\end{array}$ & $\begin{array}{c}\varphi \\
\left(^{\circ}\right) \\
\end{array}$ & $\begin{array}{l}\varphi_{c} \\
\left({ }^{\circ}\right)\end{array}$ & $\begin{array}{c}c \\
(\mathrm{kPa})\end{array}$ & $\mathrm{R}$ \\
\hline \multicolumn{5}{|l|}{ Wheat } \\
\hline 4.1 & 27.2 & 25.0 & 0.36 & 0.993 \\
\hline 6.2 & 26.8 & 25.1 & 0.36 & 1.000 \\
\hline 8.3 & 27.1 & 24.9 & 0.33 & 0.998 \\
\hline 10.3 & 26.0 & 25.4 & 0.33 & 0.999 \\
\hline 13.8 & 25.9 & 25.2 & 0.45 & 1.000 \\
\hline 17.2 & 25.7 & 26.1 & 0.24 & 1.000 \\
\hline 20.7 & 26.2 & 26.2 & 0.27 & 0.999 \\
\hline avg $\pm \mathrm{SD}$ & $26.4 \pm 0.6$ & $25.4 \pm 0.5$ & $0.33 \pm 0.07$ & \\
\hline \multicolumn{5}{|l|}{ Soybean meal } \\
\hline 4.1 & 37.3 & 31.3 & 0.78 & 0.995 \\
\hline 6.2 & 38.0 & 30.6 & 0.77 & 1.000 \\
\hline 8.3 & 36.5 & 32.6 & 0.66 & 0.999 \\
\hline 10.3 & 37.1 & 34.7 & 0.55 & 0.999 \\
\hline 13.8 & 35.3 & 34.7 & $0.24[\mathrm{a}]$ & 1.000 \\
\hline 17.2 & 35.0 & 34.1 & 0.47 & 0.999 \\
\hline 20.7 & 34.3 & 33.3 & 0.71 & 1.000 \\
\hline avg $\pm \mathrm{SD}$ & $36.2 \pm 1.4$ & $33.0 \pm 1.6$ & $0.66 \pm 0.12$ & \\
\hline \multicolumn{5}{|l|}{ Corn meal } \\
\hline 4.1 & 35.5 & $26.9[\mathrm{a}]$ & 0.82 & 0.999 \\
\hline 6.2 & 36.6 & 29.4 & 0.72 & 0.999 \\
\hline 8.3 & 35.7 & 29.6 & 0.74 & 0.999 \\
\hline 10.3 & 35.6 & 29.8 & 0.36 & 0.997 \\
\hline 13.8 & 35.8 & 30.6 & 1.02 & 1.000 \\
\hline 17.2 & 34.9 & 32.0 & 0.62 & 1.000 \\
\hline 20.7 & 35.8 & 31.6 & $2.06^{[a]}$ & 0.998 \\
\hline $\operatorname{avg} \pm \mathrm{SD}$ & $35.7 \pm 0.5$ & $30.5 \pm 1.1$ & $0.71 \pm 0.22$ & \\
\hline
\end{tabular}

[a] Outlier values are excluded from the estimation of the average and standard deviation.

corn meal it was about double, with values of $0.70 \pm 0.10 \mathrm{kPa}$ and $0.71 \pm 0.22 \mathrm{kPa}$, respectively. Cohesion values obtained for the three materials tested may be treated as having low cohesion according to terms set by Eurocode 1 (1995).

\section{Force-Displacement Characteristics}

Soybean and corn meal having approximately equal strength parameters $\varphi, \varphi_{c}$, and $c$ reveal distinctly different force-displacement characteristics. The characteristics for the two materials sheared under $20.7 \mathrm{kPa}$ of vertical pressure are shown in figure 7 . The frictional force of soybean meal attained a critical state (asymptotic value) after a displacement of $35 \mathrm{~mm}$, while for ground corn it took $60 \mathrm{~mm}$. Consequently, the secant modulus of soybean meal was considerably higher, indicating the tangential stiffness of the material. Another difference in the behavior of the two materials is the stick-slip effect observed for corn meal. The stick-slip variation in the frictional force had an amplitude of approximately $300 \mathrm{~N}$, or $15 \%$, for $2200 \mathrm{~N}$ of frictional force. Frictional parameters were estimated using the maximum values of force to obtain the largest values of the parameters.

A probable reason for the observed stick-slip was the high compressibility of corn meal. Stick-slip may be considered as a sequence of compaction-dilation events around the areas of shear zones developing in the material. Compaction

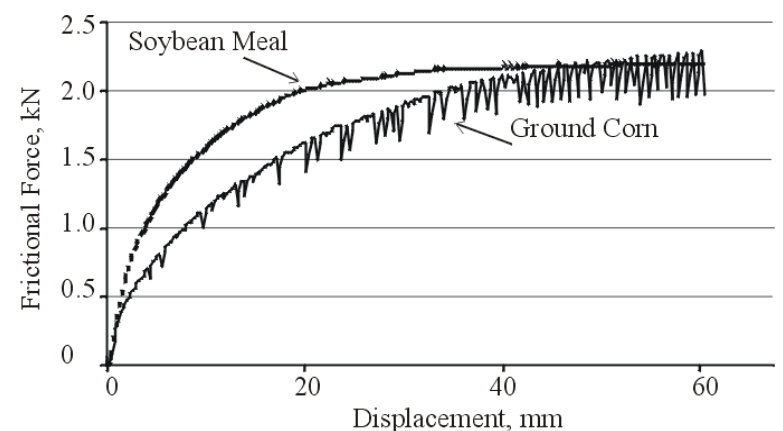

Figure 7. Typical frictional force-displacement test curves for soybean meal and corn meal at a vertical pressure of $20.7 \mathrm{kPa}$.

results in an increase of material strength and the ability to withstand higher shear loads. Exceeding the maximum strength was associated with dilation in the shear zone, reorientation of stresses, and a sharp decrease in the shear load. This ramp was immediately followed by a period of slower increase in strength that resulted from material compaction in a new shear zone. Frictional vibrations influenced sample strength and brought additional difficulties in interpretation of test results.

In industrial practice, stick-slip effects appear in silos as vibrations (silo music) or shocks (silo quake). Such effects have to be avoided in silos for many reasons (Tejchman and Gudehus, 1993). In the worst case, vibrations can cause silo failures. Tejchman and Gudehus stated that the wall roughness, the kind of silo outlet, and the material elastic properties had a significant effect on the frequency and the amplitude of the vibrations. Bucklin et al. (1996) studied stick-slip behavior between wheat and galvanized steel. A decrease in amplitude of frictional force vibrations was observed with an increase in displacement velocity. The velocity at which stick-slip behavior ended was defined as critical velocity. The authors found a statistically significant relationship between the coefficient of friction and critical velocity, but no significant influence of pressure on critical velocity was observed. Tejchman (1999) suggested several solutions to prevent frictional vibrations in a silo, including increasing wall roughness, stiffening of the silo wall, and circumferential filling. In general, it may be stated that the change of parameters of a mechanical vibrating system leads to a change in frequency and amplitude of vibration, but an efficient model of a silo as vibrating system is not yet available for design purposes.

\section{Elastic Parameters and Pressure Ratio}

Table 3 presents the elastic material parameters $v$ and $E$ for corn meal, soybean meal, and wheat. The parameter $k$ shown in table 3 is the ratio of horizontal stress $\left(\sigma_{x}\right)$ to vertical stress $\left(\sigma_{z}\right)$ measured at the end of initial compaction $\left(\sigma_{z}=100 \mathrm{kPa}\right.$, point A in fig. 2). Since literature on the mechanical properties of corn meal and soybean meal is scarce, only

Table 3. Average and standard deviation of Young's modulus $(E)$, Poisson's ratio $(v)$, and stress ratio $(k)$ for wheat, soybean meal, and corn meal.

\begin{tabular}{lccc}
\hline Material & $v$ & $E(\mathrm{MPa})$ & $k$ \\
\hline Wheat & $0.19 \pm 0.015$ & $22.4 \pm 1.2$ & $0.355 \pm 0.008$ \\
Soybean meal & $0.26 \pm 0.017$ & $10.0 \pm 2.1$ & $0.481 \pm 0.017$ \\
Corn meal & $0.21 \pm 0.012$ & $12.2 \pm 1.1$ & $0.333 \pm 0.020$ \\
\hline
\end{tabular}


parameters of wheat will be compared with results of other researchers.

Poisson's ratio of soybean meal $(0.26 \pm 0.017)$ was $24 \%$ higher than $v$ of corn meal $(0.21 \pm 0.012)$, in contrast to frictional parameters of soybean and corn meal that were not distinctly different. Poisson's ratio for wheat $(0.19 \pm 0.015)$ was lower than that of the other two materials and also lower than $v$ of 0.29 reported by Zhang et al. (1988) for wheat in comparable conditions. Differences in Young's modulus $(E)$ for soybean meal $(10.0 \pm 2.1 \mathrm{MPa})$ and corn meal $(12.2 \pm 1.1 \mathrm{MPa})$ were not large considering the high standard deviations of this parameter. Young's modulus for wheat was almost double the value of the ground materials. Young's modulus for wheat was measured as $22.4 \pm 1.2 \mathrm{MPa}$, which was higher than the range in $E$ values of 9.3 to 15.5 $\mathrm{MPa}$ reported by Zhang et al. (1988), which increased with an increase in vertical pressure.

The stress ratio $(k)$ for soybean meal was $0.481 \pm 0.017$, which was considerably higher than the value $(0.333 \pm 0.020)$ obtained for corn meal. The measured value of $k$ for wheat was $0.355 \pm 0.008$, which was in good agreement with results of Zhang et al. (1994), who reported stress ratios in the range of 0.32 to 0.43 for pressures ranging from $2 \mathrm{kPa}$ to $400 \mathrm{kPa}$.

A number of equations relating $k$ to the angle of internal friction $(\varphi)$ have been proposed (Lohnes, 1993). Stress ratio can be also derived from the theory of elasticity (Lambe and Whitman, 1969) as a function of Poisson's ratio:

$$
k=\frac{v}{1-v}
$$

Jaky (according to Lohnes, 1993) derived a relationship for the at-rest state of stress:

$$
k=\frac{(1-\sin \varphi)\left(1+\frac{2}{3} \sin \varphi\right)}{1+\sin \varphi}
$$

Equation 6 was modified and recommended by Eurocode 1 (1995) as:

$$
k=1.1(1-\sin \varphi)
$$

Calculated values of $k$ using equations 10 through 12 are presented in table 4 together with the mean results from table 3 .

Estimation of $k$ based on the theory of elasticity (eq. 10) resulted in a value of the parameter distinctly lower than the experimental results. Eurocode 1 recommended equation 12 to estimate $k$, which gave a value higher than the experimental values. Jaky's equation (eq. 11) provided an estimate for $k$ that was closest to the experimental value.

Table 4. Experimental values for stress ratio $(k)$ and predicted values calculated using equations 10, 11, and 12 for wheat, soybean meal, and corn meal.

\begin{tabular}{lcccc}
\hline & Experimental & Eq. 10 & Eq. 11 & Eq. 12 \\
\hline Wheat & 0.355 & 0.235 & 0.498 & 0.666 \\
Soybean meal & 0.481 & 0.351 & 0.359 & 0.491 \\
Corn meal & 0.333 & 0.266 & 0.365 & 0.500 \\
\hline
\end{tabular}

CONCLUSIONS

A modified direct shear apparatus was shown to be a useful tool for estimation of frictional properties of biological-based granular materials. Strength parameters $c, \varphi_{\mathrm{c}}$, and $\varphi$ were in good agreement with data published earlier by various authors. The grain tester was relatively easy to operate; vertical loads were applied by means of compressed air, and there was no need for moving weights. Longer shear displacement than in standard direct shear apparatuses were available without a decrease in shear area; hence, no correction in stress calculations for decreasing shear area were necessary.

Yield loci of corn meal, soybean meal, and wheat were found linear in the range of applied consolidation pressure (up to $34 \mathrm{kPa}$ ). The materials obeyed Coulomb's yield condition. Angles of friction of soybean meal $(\varphi=$ $\left.36.2^{\circ} \pm 1.4^{\circ}, \varphi_{c}=33.0^{\circ} \pm 1.6^{\circ}\right)$ and corn meal $(\varphi=$ $\left.35.7^{\circ} \pm 0.5^{\circ}, \varphi_{c}=30.5^{\circ} \pm 1.1^{\circ}\right)$ were similar. Angles of friction of wheat found $\varphi$ equal to $26.4^{\circ} \pm 0.6^{\circ}$ and $\varphi_{c}$ equal to $25.4^{\circ} \pm 0.5^{\circ}$ and were in good agreement with earlier reported data. Values of cohesion $(c)$ for wheat, soybean meal, and corn meal were found to be $0.33 \pm 0.07 \mathrm{kPa}$, $0.70 \pm 0.1 \mathrm{kPa}$, and $0.71 \pm 0.22 \mathrm{kPa}$, respectively.

The frictional force-displacement characteristics of soybean meal and corn meal, below the critical state unlike the strength parameters, were distinctly different. During shearing under a normal load of $20.7 \mathrm{kPa}$, the frictional force for soybean meal stabilized after $20 \mathrm{~mm}$, while in the case of corn meal, the frictional force did not stabilize within $60 \mathrm{~mm}$ of displacement. Corn meal showed higher compressibility than soybean meal. At a vertical pressure of $34.4 \mathrm{kPa}$, the density of corn meal increased by $21 \%$, while the density of soybean meal increased by approximately $5 \%$.

Values of Young's modulus $(E)$ for soybean meal and corn meal were $10.0 \pm 2.1$ and $12.2 \pm 1.1 \mathrm{MPa}$, respectively. Values of Poisson's ratio for soybean meal and corn meal were distinctly different, with values of $0.26 \pm 0.017$ and $0.21 \pm 0.012$, respectively. The lateral-to-vertical stress ratio $(k)$ of soybean meal $(0.481 \pm 0.017)$ was the highest, and $k$ of corn meal $(0.333 \pm 0.020)$ was the lowest. For wheat, $k$ was $0.355 \pm 0.008$, which was in good agreement with earlier published results. The stress ratio estimated using Jaky's theoretical equation gave the best approximation to experimental results for the examined equations. A probable reason for the difference in mechanical behavior of soybean meal and corn meal was the difference in particle size distribution and/or the difference in chemical properties of the whole seed, which could be a result of the higher fat content of soybean meal.

Relatively high compressibility of agricultural materials poses particular difficulties during testing. Large dimensions of the test sample are generally considered preferable when testing granular materials. However, a high volume of the sample combined with high compressibility resulted in a strong elastic reaction of the system, causing stick-slip effects. Stick-slip may be considered a sequence of compaction-dilation events around the areas of shear zones formed in the material. Compaction resulted in an increased material strength, and an ability to withstand a higher shear load. Exceeding the maximum strength was associated with dilation in the shear zone, reorientation of stresses, and a sharp decrease in shear load. This ramp was immediately 
followed by a period of slower increase in strength that resulted from material compaction in new shear zones. Frictional vibrations influenced sample strength and brought additional difficulties in interpretation of test results. In industrial practice, stick-slip effects appear in silos as vibrations or shocks. Currently there is no clear model of frictional vibration, and the phenomenon needs further investigations.

\section{ACKNOWLEDGEMENTS}

The authors wish to express their appreciation to the College of Agriculture, University of Kentucky, for sponsoring Dr. Molenda's visit to the Biosystems and Agricultural Engineering Department, which made the research reported in this article possible. The part of the research performed in Poland was supported by the Polish Committee of Scientific Research under Grant No. 5 PO6F 02117.

\section{REFERENCES}

ASAE Standards. 1997a. S319.3: Method of determining and expressing fineness of feed materials by sieving. St. Joseph, Mich.: ASAE.

1997b. S352: Moisture measurement, unground grain and seeds. St. Joseph, Mich.: ASAE.

Bell, T. A., B. J. Ennis, R. J. Grygo, W. J. F. Scholten, and M. M. Schenkel. 1994. Practical evaluation of the Johanson hang-up indicizer. Bulk Solids Handling 14(1): 117-125.

Benson, W. L. 1976. Obtaining and maintaining quality Premixing and processing. In Feed Manufacturing Technology, 260-263. H. B. Pfost, ed. Arlington, Va.: Feed Production Council, American Feed Manufacturers Association, Inc.

Bucklin, R. A., M. Molenda, T. C. Bridges, and I. J. Ross. 1996. Slip-stick frictional behavior of wheat on galvanized steel. Trans. ASAE 39(2): 649-653.

Cook, A. 1976. Flow of bulk solids in bins. In Feed Manufacturing Technology, 465-470. H. B. Pfost, ed. Arlington, Va.: Feed Production Council, American Feed Manufacturers Association, Inc.

Clower, R. E., I. J. Ross, and G. M. White. 1973. Properties of compressible granular materials as related to forces in bulk storage structures. Trans. ASAE 16(3): 478-481.

Eurocode 1. 1995. Basis of design and actions on structures: Part 4. Actions in silos and tanks. Brussels, Belgium: European Committee for Standardization.

Jenike, A. W. 1961. Gravity flow of bulk solids. Bulletin No. 108 of the University of Utah (52) 29. Salt Lake City, Utah: University of Utah.

Johanson, J. R. 2000. Smooth out solids blending problems. Chemical Eng. Progress 96(4): 21-37.

Knowlton, T. M., J. W. Carson, G. E. Klinzing, and W.-C. Yang. 1994. The importance of storage, transfer, and collection. Chemical Eng. Progress 90(4): 44-54.
Lambe, T. W., and R. V. Whitman. 1969. Soil Mechanics. New York, N.Y.: John Wiley and Sons.

Lohnes, R. A. 1993. Lateral stress ratios for particulate materials. Powder Handling and Processing 5(4): 331-335.

Molenda, M., S. A. Thompson, and I. J. Ross. 2000. Friction of wheat on corrugated and smooth galvanized steel surfaces. $J$. Agric. Eng. Research 77(2): 209-219.

Sawicki, A. 1994. Elasto-plastic interpretation of oedometric test. Archives of Hydro-Eng. and Environmental Mechanics 41(1-2): 111-131.

Tejchman, J. 1999. Technical concept to prevent the silo honking. Powder Technology 106(1999): 7-22.

Tejchman, J., and G. Gudehus. 1993. Silo-music and silo-quake experiments and a numerical Cosserat approach. Powder Technology 76(1993): 201-212.

Thompson, S. A., and I. J. Ross. 1983. Compressibility and frictional coefficients of wheat. Trans. ASAE 26(4): 1171-1180.

USDA. 1999. Official standards for grain. Washington, D.C.: USDA, Grain Inspection, Packers, and Stockyards Administration.

Wilms, H. 1991. Criteria for evaluation of silo design codes. Bulk Solids Handling 11(1): 55-59.

Zhang, Q., V. M. Puri, H. B. Manbeck, and M. C. Wang. 1988. Elastoplastic constitutive parameters of en masse wheat for a cyclic load model. Trans. ASAE 16(3): 910-916.

Zhang, Q., V. M. Puri, and H. B. Manbeck. 1994. Applicability of two-parameter failure criterion to wheat en masse. Trans. ASAE 37(2): 571-575.

\section{NOMENCLATURE}

$a$

$c$

$k$

A

E

$E^{*}$

$\varepsilon_{x}^{e}$

$\varepsilon_{z}^{e}$

$\varphi$

$\varphi_{c}$

$\rho_{\mathrm{o}}$

$\rho$

$\sigma$

$\sigma_{r}$
$=$ slope of the linear part of the unloading path in $\sigma_{x}$ and $\sigma_{z}$ coordinates

$=$ cohesion

$=$ stress ratio

= parameter for bulk density relationship

= Young's modulus

$=$ slope of the linear part of unloading path in the $\sigma_{x}$ and $\varepsilon_{z}$ space

$=$ horizontal strain

$=$ vertical strain

$=$ effective angle of internal friction

$=$ angle of internal friction

$=$ uncompacted bulk density $\left(\mathrm{kg} / \mathrm{m}^{3}\right)$

= compacted bulk density $\left(\mathrm{kg} / \mathrm{m}^{3}\right)$

$=$ vertical pressure $(\mathrm{kPa})$

$=$ vertical consolidation reference pressure $(\mathrm{kPa})$

$\sigma_{z 1}, \sigma_{z 2}, \sigma_{z 3}=$ vertical pressures $(\mathrm{kPa})$

$\checkmark=$ Poisson's ratio 